\title{
Industry 4.0 implementation sequence for manufacturing companies
}

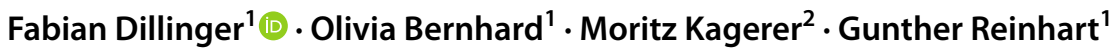

Received: 3 October 2021 / Accepted: 25 January 2022 / Published online: 24 February 2022

(c) The Author(s) 2022

\begin{abstract}
As a result of increasing globalization, manufacturing companies are confronted with rising costs and time pressure. A possibility to counter these challenges is Industry 4.0, which focuses on optimizing industrial processes and is characterized by the digitalization and networking of all value chain participants. This paper elaborates the one-to-one interrelation between relevant Industry 4.0 technologies using the Delphi study method and interdependency matrices. Based on this, an Industry 4.0 implementation sequence for manufacturing companies is derived and validated by experts. The contribution shall serve as an essential basis for companies to implement Industry 4.0 in their production.
\end{abstract}

Keywords Industry $4.0 \cdot$ Industrie $4.0 \cdot$ Interdependency $\cdot$ Implementation sequence $\cdot$ Strategy $\cdot$ Production $\cdot$ Smart factory $\cdot$ Smart manufacturing

\section{Introduction and motivation}

Due to globalization, mass personalization, and saturated markets, manufacturing companies face a complex production environment characterized by rising quality requirements, steadily shortening product life cycles, and significant cost pressure on production processes across the entire value chain $[1,2]$. A more flexible organizational structure and the optimization and digitalization of production processes in the sense of Industry 4.0 are required to counter these challenges [3]. Industry 4.0 focuses on enhancing companies' processes, products, and business models [4] and is characterized by the digitalization and intelligent networking of all value chain participants in real-time $[5,6]$.

Fabian Dillinger

fabian.dillinger@tum.de

Olivia Bernhard

olivia.bernhard@tum.de

Moritz Kagerer

mkagerer@sternstewart.com

Gunther Reinhart

gunther.reinhart@tum.de

1 Institute for Machine Tools and Industrial Management, Technical University of Munich, Boltzmannstr. 15, Garching b. München, 85748 Munich, Germany

2 Stern Stewart \& Co., Salvatorplatz 4, 80333 Munich, Germany
Therefore, various innovative technologies are used, such as sensors, predictive maintenance, or cloud technologies [7]. The implementation and interaction of the technologies lead to comprehensive efficiency, cost, and flexibility benefits and secure future competitiveness for manufacturing companies [8]. For example, machine data can be collected in real-time using sensors and analyzed by AI technologies to predict machine failure [9]. In this way, machine runtimes can be extended and maintenance and production costs reduced. The machine's real-time information can also be shared with customers and suppliers to adjust production sequencing, and inventories in the supply chain can be reduced [10].

However, small and medium-sized manufacturing enterprises have problems implementing Industry 4.0 technologies in a structured and targeted manner in production. The main reasons are the lack of know-how and transparency, which also leads to a missing implementation strategy. [11] Consequently, it is essential to analyze the impact and type of the one-to-one interdependencies between relevant Industry 4.0 technologies to support manufacturing companies in creating a reference implementation strategy [6].

Therefore, this scientific paper provides an overview of the one-to-one correlations of Industry 4.0 technologies and presents an Industry 4.0 reference implementation sequence for manufacturing companies. Thus, this contribution supports manufacturing companies in designing implementation sequences and empowers them to create a self-managed digital transformation process. The following section sets up 
the reference frame of the paper's scientific fields and introduces Industry 4.0. Afterward, the current state of research and a methodological approach to create an implementation sequence are presented. Based on this, the Industry 4.0 interdependencies are elaborated, and an implementation sequence is derived. Finally, the implementation sequence is validated by experts from industry and science.

\section{Fundamentals of Industry 4.0}

Industry 4.0 aims to optimize industrial value creation and shapes the redesign, realignment, and further development of existing production systems [12]. This digital transformation is characterized by digitizing and networking all products, processes, and business models in the manufacturing industry [13] to effectively and efficiently design material and information flows along the value chain [7]. Industry 4.0 incorporates a variety of different technologies [14]. According to Ruessmann et al. [15], Gilchrist [16], and Wang AND Wang [17], nine major technology fields enable industrial production transformation. The main technology fields are shown in the following figure (Fig. 1). In the illustration, augmented reality has been replaced by assistance systems since augmented reality, as cognitive assistance systems, is a part of the higher-level technology field of assistance systems [18-20]. The fields are clustered by smart interaction, smart data, and smart operation. [19]

The technology field simulation can be used to represent actual conditions virtually [15]. For example, machine

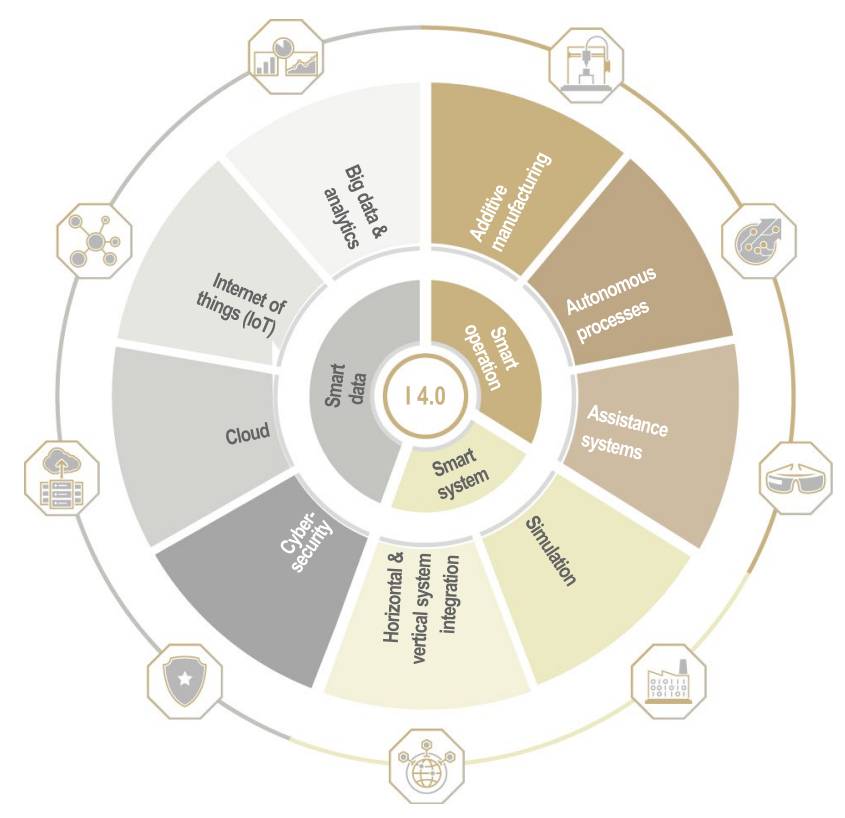

Fig. 1 Overview of Industry 4.0 main technology fields according to Ruessmann et al. [15] and Gilchrist [16] processes can be evaluated in advance using data transmitted in real-time [15]. Thus, simulations can be used to validate and adapt complex issues or processes before real-world application [2]. Another leading technology field is assistance systems that support the employee on a cognitive or physical level in performing his or her activities in the work environment $[2,21,22]$. Autonomous processes assist in accomplishing complex tasks or perform them entirely on their own and present another leading technology in Industry 4.0. As, e.g., autonomous robots evolve into increasingly flexible and cooperative constructs, automation will also continue to advance. [15] Supplementary, the internet of things (IoT) describes the networking of objects from the real world with their representatives from the virtual world and aims to connect large numbers of objects through standardized technologies [15, 23]. In addition, according to Ruessmann et al. [15] and Mell and Grance [24], cloud technology provides a possibility for sharing, exchanging, and editing data over the internet by networking computer systems. The consequence of new Industry 4.0 technologies is increasing connectivity and communication, which requires protecting production systems [15]. Cybersecurity intends to secure sensitive and confidential company data and, therefore, is an essential technology field [23]. Additive manufacturing involves the direct generation of components according to automated layer construction principles. By relying on computer-internal data models, additive manufacturing belongs to the generative manufacturing processes. The successively applied layers ensure that the desired final geometry is achieved [15, 25, 26]. Furthermore, horizontal and vertical system integration creates complete integration across all functional and corporate levels leading to robust and efficient networking of different participants across the value chain [15, 27]. Another leading technology is big data and analytics which goal is to collect and analyze large amounts of data from various processes in real-time. The data is provided by production systems or machines as well as e. g. from Customer-Relationship-Management (CRM) or Enterprise Ressource Planning (ERP) systems. In addition, data analytics can identify patterns in complex data sets to make predictions about future behavior by using, e.g., artificial intelligence solutions [15, 23].

\section{State of the art}

This section presents the state of research based on a comprehensive literature analysis to identify and analyze relevant Industry 4.0 implementation sequence models. In addition, maturity models were considered, which indicate an idealized implementation sequence for a specific area based on best or common practice knowledge [28]. Thus, the selected maturity models include Industry 4.0 implementation 
sequences, which can be used as additional references. The following figure provides an overview of the literature sources contributing to the listed number of Industry 4.0 models for further selection (Fig. 2).

In total, more than 250 Industry 4.0 models could be found by analyzing the contributions of fourteen authors. Additional models were identified by conducting a literature review using the providers OPAC, Gateway Bayern, ScienceDirect, Research Gate, and Google Scholar. The search terms Industry 4.0, implementation strategy, implementation sequence, maturity model, readiness, and roadmap were used and linked with logical operators of Boolean algebra for conjunction (and) and disjunction (or). For the pre-selection, duplicates were removed and also filtered by using the following criteria:

- Topic: Industry 4.0

- Focus: Production

- Documentation: Scientific documentation

- Accessibility: Public accessibility

- Document types: Conference papers, reviews, and articles

- Subject area: Engineering

As a result, 30 Industry 4.0 models have been identified and systematically analyzed in two steps. First, the models were characterized by their type, scope, and nine technology fields. The technology fields shown in Fig. 2 were used, as they represent the essential technology areas of Industry 4.0 [15] and are thus crucial for a holistic implementation sequence [16]. In addition to step one, the transparent presentation of Industry 4.0 technologies' interdependencies is also of decisive importance for developing and introducing an implementation sequence. Therefore, the models that meet the requirements were examined in a subsequent step to determine whether they include the Industrie 4.0 technologies' interdependencies. The result of the first step is presented in the following figure (Fig. 3).

As shown in Fig. 3, most models originate from research projects or scientific contributions $(80 \%)$, and $70 \%$ are not suitable for self-application. The need for an external application implies that the models are not freely available or very complex in their application. In contrast, a user-friendly and transparent self-application is a critical success factor in creating a company-specific Industry 4.0 implementation sequence. Moreover, the "Industrie 4.0 Maturity Index" by Schuh et al. [53], the "decision support model for implementing Industry 4.0 methods" by Liebrecht et al. [41], and the "maturity levelbased assessment tool" by Rauch et al. [51] are the only models that include at least more than seven of the nine main technology fields. Therefore, these three models are further investigated concerning the Industry 4.0 technologies' one-to-one interdependency. The Industrie 4.0 Maturity Index [53] and the model presented by Rauch et al. [51] do not provide a comprehensive one-to-one interdependency matrix to generate transparency on their interaction and implications for manufacturing companies. The model presented by Liebrecht et al. [41] is based on sixty Industry 4.0 methods, e.g., paperless manufacturing or change management, which the authors derived from industry projects and over 200 use cases described on two different internet platforms. The Industry 4.0 methods are linked in a correlation matrix using literature analysis and expert workshops. The procedure for deriving the matrix is not described in detail. Afterward, the authors derive an implementation sequence based on a System Dynamics model to support companies. The scientific contribution of
Fig. 2 Methodical selection of implementation models for Industry 4.0

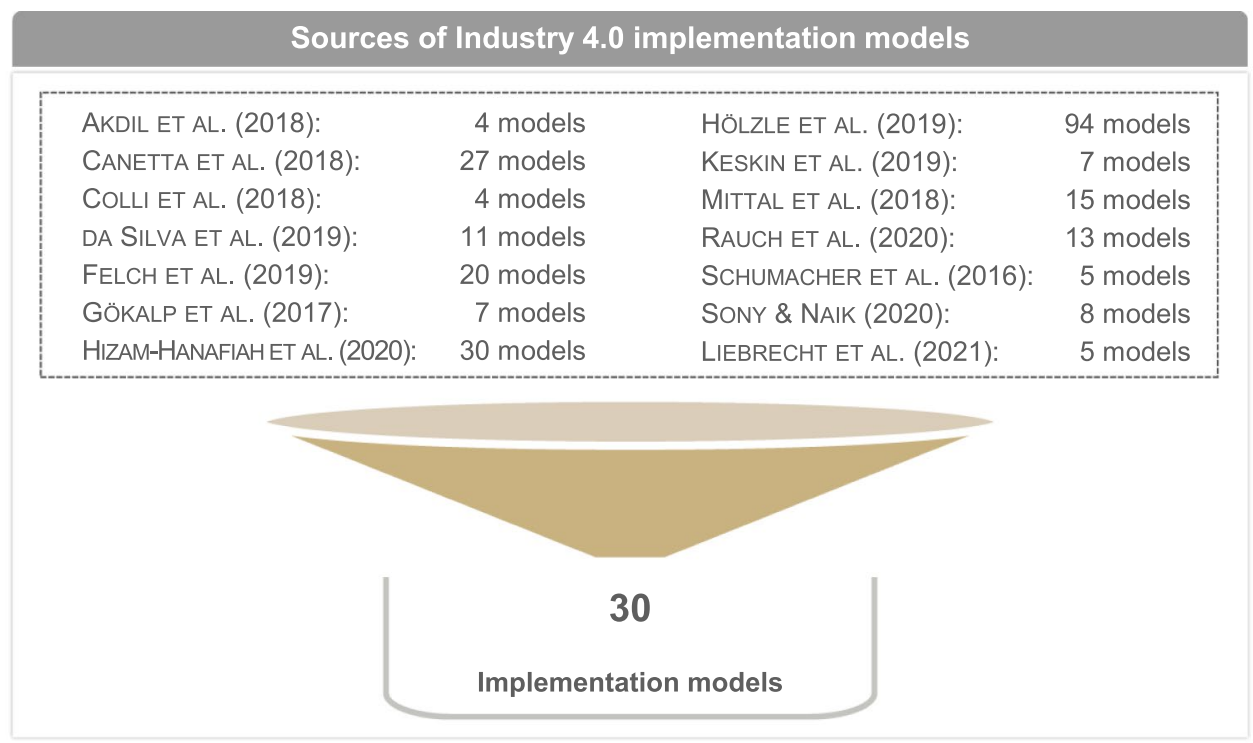


Fig. 3 Analysis result of the investigated Industry 4.0 implementation models

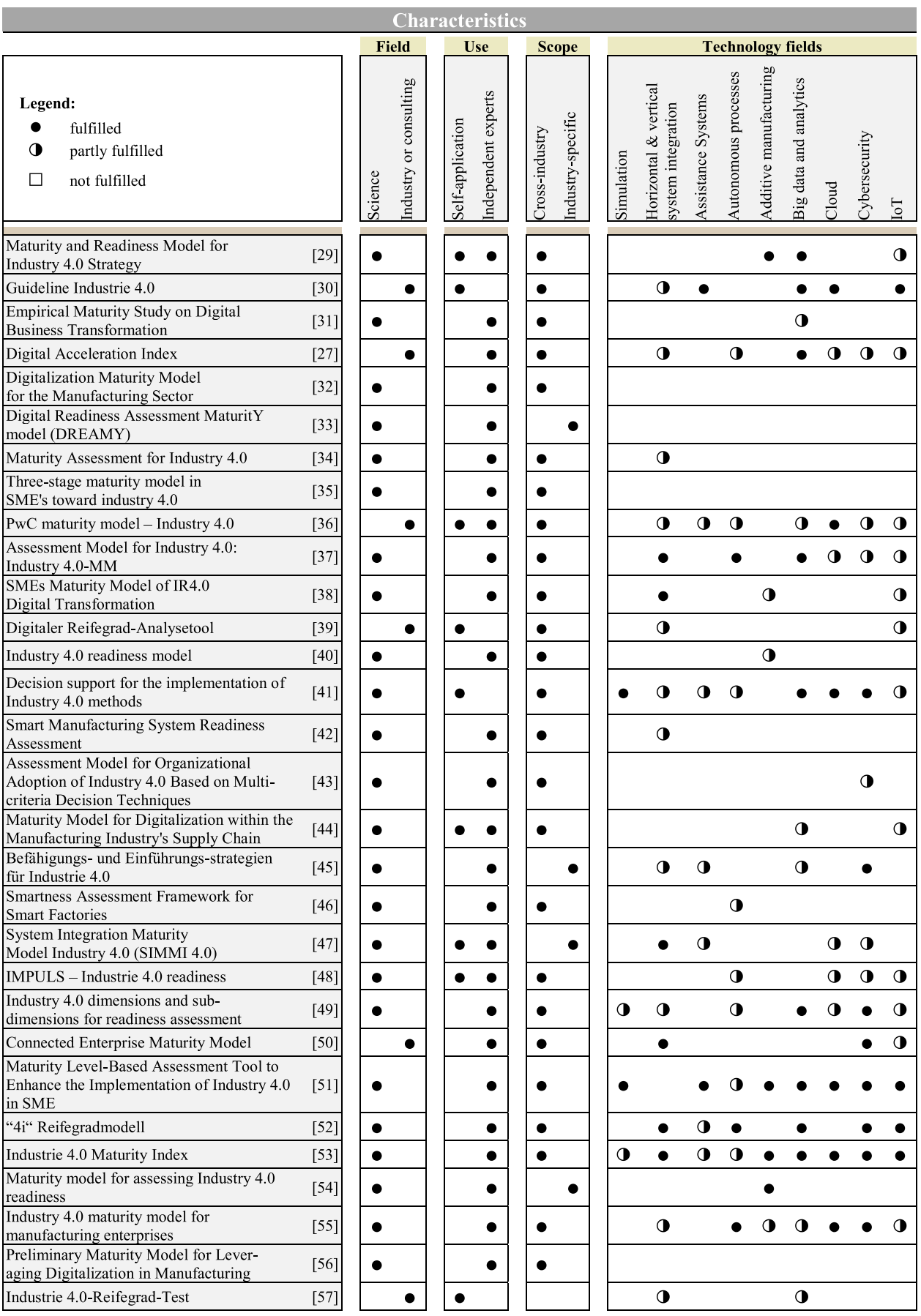

Liebrecht et al. [41] covers a wide range of Industrie 4.0 methods, but it does not include all nine technology fields or advanced technologies in equal measure.

However, the identified models provide an excellent scientific basis for analyzing the interdependencies and validating the Industry 4.0 implementation sequence. Especially the approach of Liebrecht et al. [41] can be used and extended by a, e.g., comprehensive bibliometric literature analysis using text mining algorithms or a Delphi study method.

\section{Methodical approach}

The following methodical, application-oriented approach is presented to identify a one-to-one correlation of relevant Industry 4.0 technologies and to derive a reference implementation sequence. Such a correlation matrix should be based on a clear production perspective and include Industry 4.0 technologies of considerable importance for manufacturing companies. Moreover, the targeted matrix and implementation sequence shall be based on a proven, systemic, 
and methodical planning procedure, as Aull [58], Dillinger et al. [59], and Liebrecht et al. [41] presented.

The approach can be divided into three major phases (Fig. 4). In the first phase, the relevant technologies need to be selected. Therefore, a structured literature review as presented by Rowley AND Slack [60] and an analysis of various use cases based on the platform Industry 4.0 [61] are to be conducted. In addition, the selection needs to be validated and adjusted through online surveys and semistructured expert interviews with participants from science and industry. This multi-stage process ensures that research and industry perspectives are considered and that innovative technologies relevant to manufacturing companies are identified and selected. Moreover, technology profiles are prepared for the selected technologies to ensure a consistent understanding in the subsequent phases.

The selected technologies provide the basis for phase two, in which the type and impact of the one-to-one Industry 4.0 technologies' interactions need to be investigated. The technologies' interrelation can be positive, negative, or independent. Therefore, a literature review, an analysis of Industry 4.0 use cases based on the Plattform Industry 4.0 [61], and an initial Delphi study [62] with experts from industry and science will be conducted.
With the help of the Delphi method, the reliable obtaining of consensus of expert opinions should be achieved [63]. Thus, the Delphi method focuses on solving a complex problem by gathering the individual contributions of selected experts [64]. Therefore, an anonymous, iterative feedback technique avoids mutual influence and a possibly resulting group dynamic $[63,65]$. The expert group usually comprises between 5 and 20 experts [65]. First, the Delphi study will be repeated until one correlation matrix is achieved, indicating the technologies' impact [65]. The study will be continued in step two to determine the type of correlation. The type indicates whether it is a prerequisite or a supportive relationship. In case of a prerequisite connection, "technology A" must be implemented before "technology B". A supportive relationship indicates that it has no direct influence on the implementation sequence, but the technologies positively or negatively affect each other. Therefore, the Delphi method will be continued based on the impact matrix. The result is an interdependency matrix that indicates the type and impact between the Industry 4.0 technologies.

Based on the findings of the preceding phases that are summarized in the interdependency matrix, an implementation sequence can be derived in phase 3 . The reference Industry 4.0 implementation sequence is based on the

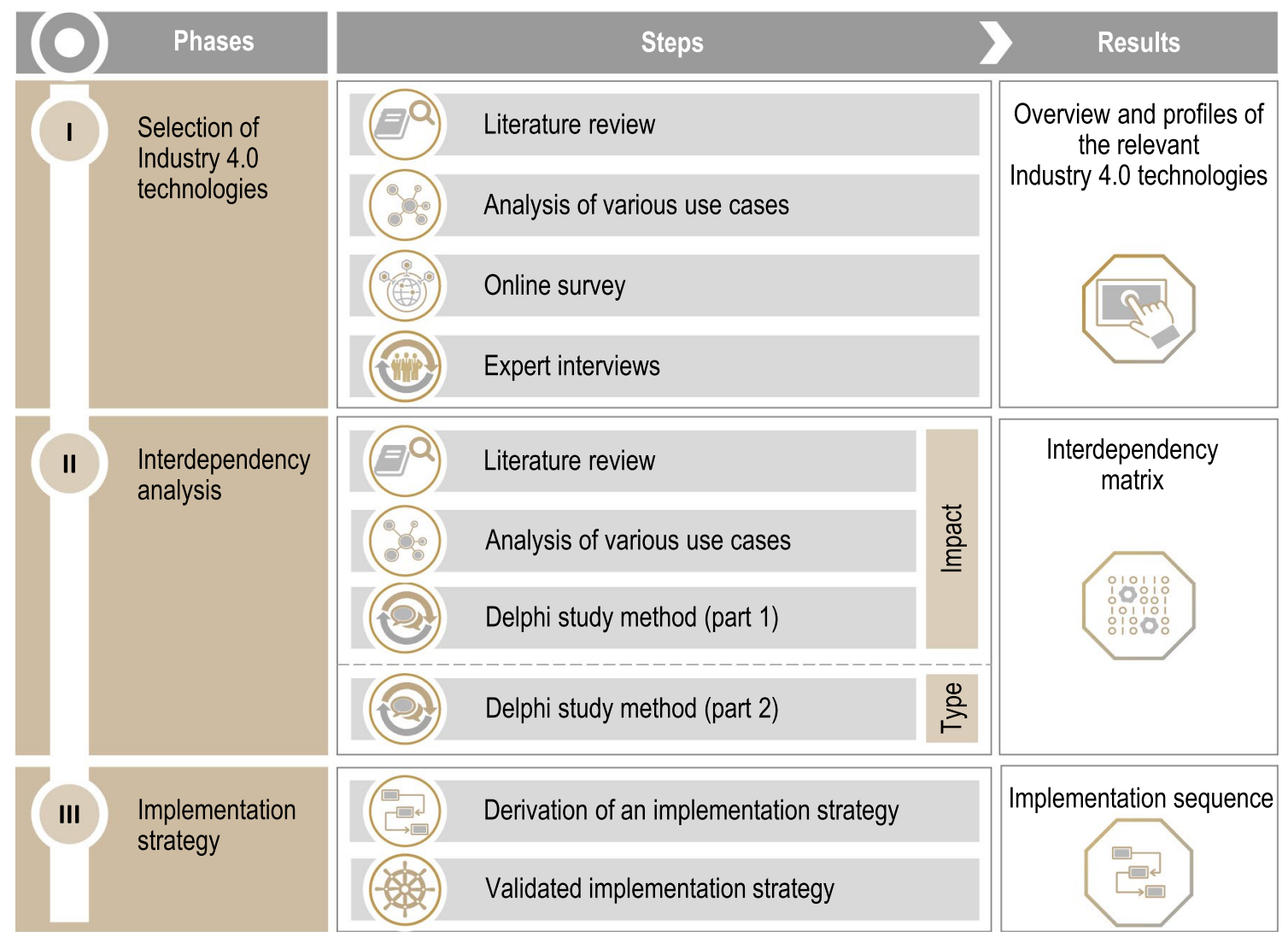

Fig. 4 Methodical approach to derive an implementation sequence 
technologies' type and impact and is subsequently validated and discussed by industry and research experts.

\section{The Industry 4.0 implementation sequence}

\subsection{Phase I: selection of the Industry $\mathbf{4 . 0}$ technologies}

First, a systematic literature analysis was carried out based on the database Scopus to preselect relevant Industry 4.0 technologies for manufacturing companies. According to the guidelines for a literature review of Rowley AND Slack [60], research categories and keywords were derived from various scientific contributions. In addition, research categories are derived from the work of e. g. Vernim et al. [66] or Wichmann et al. [67]. The nine main technology fields, shown in Fig. 2, were used as keywords.

The identified six research categories and the keywords were linked with logical Boolean algebra operators for conjunction and disjunction. The literature analysis was limited to a publication period from January 2016 to October 2020, conference papers, reviews, and articles related to the research field of engineering [66]. After the scientific contributions were preselected, the remaining 43 publications were used to identify relevant Industry 4.0 technologies.

In addition to the literature analysis, more than 300 relevant use cases from the German Federal Ministry for Economic Affairs and Energy's Industrie 4.0 platform [61] focused on production and supply chain were analyzed. The development stage of the use case technologies varies from research and development (12.5\%), demonstrators (18.2\%), market launch $(22.7 \%)$ to market maturity (46.6\%). Thus, both established and emerging Industry 4.0 technologies were considered. After conducting the literature review and the use case analysis, twenty-four highly relevant technologies for manufacturing companies could be identified.

Last, the list of preselected technologies was validated and, if required, expanded by experts from the industry and science. Therefore an online survey with 32 participants was used to assess the selected technologies concerning the manufacturing companies' success. Most experts belong to the automotive industry (34.4\%). Mechanical and plant engineering accounted for $25 \%$, construction for $12.5 \%$, electrical and electronics for $9.4 \%$, wood and furniture for $6.2 \%$, and rubber and caoutchouc for $3.1 \%$ of the survey participants. The online survey results and the semi-structured expert interviews confirm the pre-selection of Industry 4.0 technologies and expand it to include machine-to-machine communication and CAX technologies. [19]

In total, 26 Industry 4.0 technologies were identified that are highly relevant for manufacturing companies. This selection is shown in the following figure (Fig. 5). The shown clustering and the assignment of the technologies to the technology fields are based on preliminary work by the author [19] and result from bibliometric literature analyses using text mining algorithms and further comprehensive expert interviews.

Based on the selected technologies of the first phase, an interdependency analysis can be conducted to identify the one-to-one impact and type between the Industry 4.0 technologies.

\subsection{Phase II: interdependency analysis}

The goal of the second phase is to analyze the impact and type between the single Industry 4.0 technologies. First, the technologies' one-to-one impacts have been analyzed with a literature review, a use case analysis, and an initial Delphi study.

The literature review was carried out with the software VOSviewer. VOSviewer enables multi-dimensional scaling and clustering of bibliometric data. The correlations of the terms can be examined and displayed using a co-occurrence analysis. The necessary structured literature research was based on the Scopus database and referred to relevant contributions from the field of Industry 4.0. The keywords were based on the leading technology fields according to Ruessmann et al. [15], Wang AND Wang [17], and Gilchrist [16] and linked with logical Boolean algebra operations. A publication period between 2011 and 2021 and the restriction to conference papers, reviews, and articles from the research field engineering were chosen as limits. In total, more than 4.000 scientific articles could be identified for the VOSviewer analysis. Afterward, a text-mining algorithm was used to analyze the one-to-one interdependencies between the 26 Industry 4.0 technologies. Therefore, duplicates have been removed, and a thesaurus database was created for synonymous terms, such as autonomous vehicles and AGV. The result of the analysis is visualized in a two-dimensional bibliometric network in Fig. 6. The more frequently two terms are mentioned together in a scientific contribution, the closer they are located to each other in the network, and the thicker the edges between the two technologies are. The results of the literature analyses were finally transferred into an interdependency matrix by using the frequency and occurrence number of interactions.

Additionally, various industry use cases were analyzed with the help of the Industry 4.0 platform [61]. According to the first phase, 308 relevant use cases from the area of production and supply chain of German companies were examined. The analysis focused on the one-to-one impact of single Industry 4.0 technologies. For example, when introducing predictive analytics in manufacturing, realtime capable data acquisition by sensors is an essential 


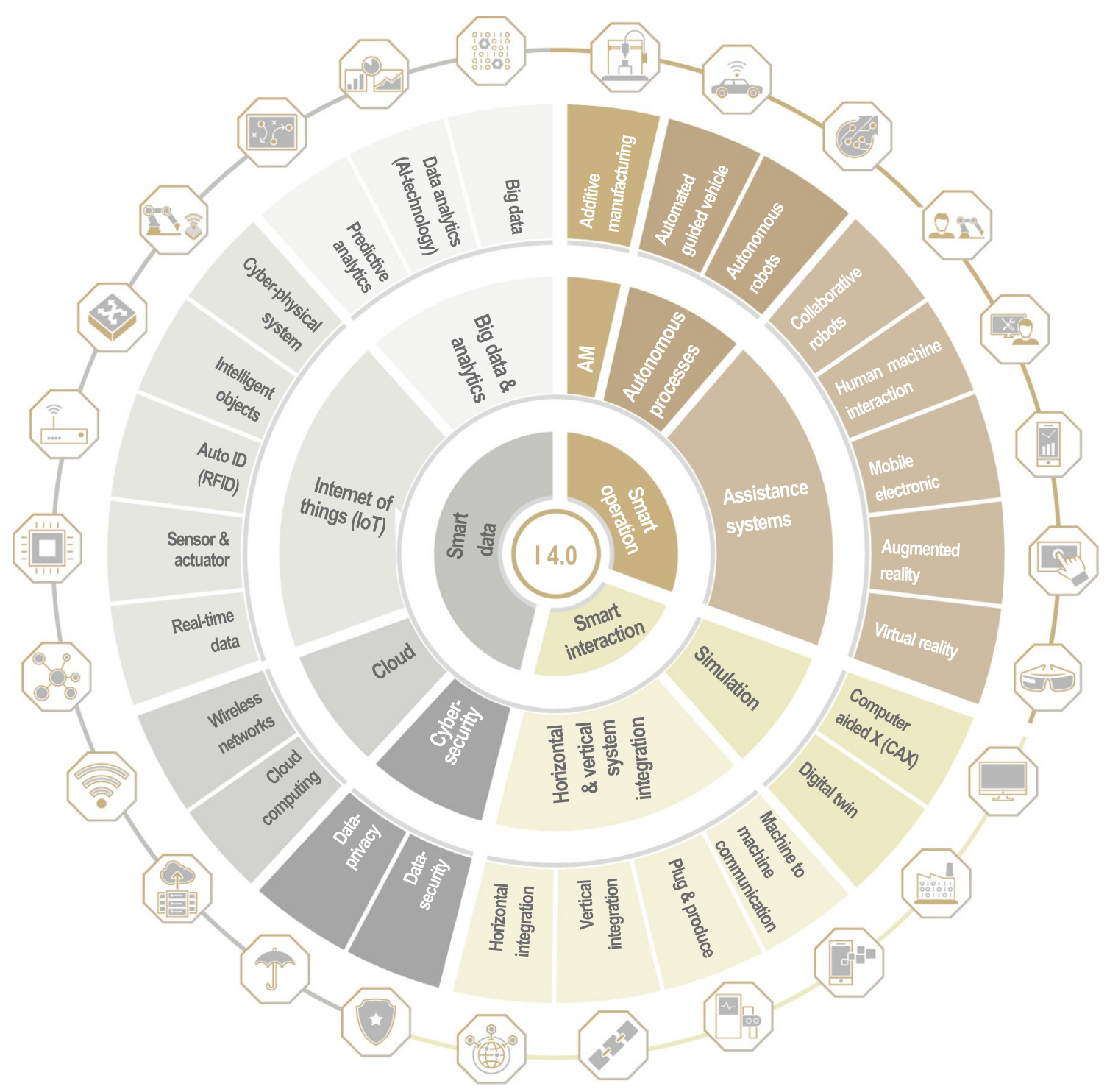

Fig. 5 Industry 4.0 technology circle according to Dillinger et al. [19]

prerequisite [61]. These results were also transferred into an interdependency matrix by considering the relative frequency of entries between the technologies. The interdependency matrices of the literature and use case analysis are essential inputs for the following Delphi study.

The Delphi study was conducted with nine experts from industry and science in two main phases over several rounds. In the first phase, the experts assessed the impact between the technologies to determine the type of interaction subsequently. As shown in Table 1, the panel sampling of the experts was heterogeneously composed to avoid biases.

First, the experts assessed the impact independently using an interdependency matrix. The evaluation was made with the help of a seven-point Likert scale (see Table 2). The scale ranged from a strong negative to a strong positive correlation impact. The maximum values $(-3 ;+3)$ were distributed equally to counteract possible influences.

After that round, the experts' individual interdependency matrices were merged with the literature review results and the interdependency matrix of the use case analysis. Therefore, the mean value and the standard deviation were calculated for each interrelation between two technologies. In the following two rounds, the experts had to validate and modify the merged interdependency matrix and assess the type of correlation between the technologies. The type of correlation between two elements can be prerequisite or supportive, as described in Sect. 4. The following interdependency matrix presents the Delphi study result, including the technology's one-to-one impact and type (see Table 3). The type is indicated with a "V" for prerequisite and a "U" for supportive. The impact varies 


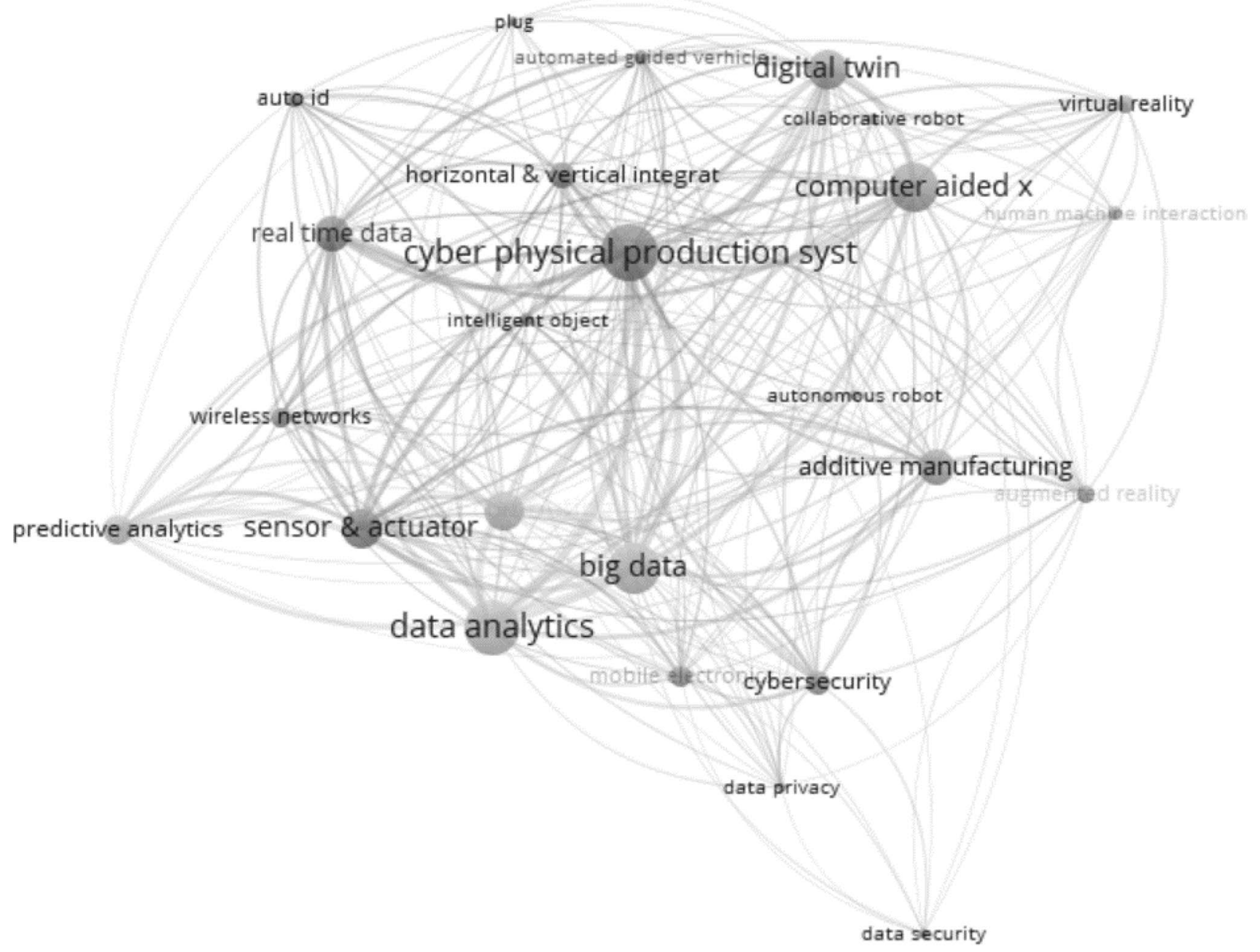

Fig. 6 Bibliometric analysis of the 26 Industry 4.0 technologies

Table 1 Anonymized overview of the panelists

\begin{tabular}{llll}
\hline Experts & Job & Company & Company type \\
\hline Expert 1 & Head of Lean & A & Automotive industry \\
Expert 2 & Head of maintenance & B & Logistics \\
Expert 3 & Scientist & C & Research institute \\
Expert 4 & Head of production & D & Mechanical Engineering \\
Expert 5 & Digital manager & E & Mechanical Engineering \\
Expert 6 & Head of Engineering & A & Automotive industry \\
Expert 7 & Project leader & F & Mechanical Engineering \\
Expert 8 & Project leader & G & Consultancy \\
Expert 9 & Project leader & C & Research institute \\
\hline
\end{tabular}

according to the Likert scale in Table 2 from a strong negative correlation $(-3)$ up to a strong positive correlation $(+3)$. The reading order of the following table is from row to column. Thus, the technology in the row is a prerequisite or support for the technology in the column.
Table 2 Likert scale for assessing the impact between the elements

\begin{tabular}{ll}
\hline Impact & Description \\
\hline-3 & Strong negative correlation impact \\
-2 & Medium negative correlation impact \\
-1 & Low negative correlation impact \\
0 & No correlation impact \\
1 & Low positive correlation impact \\
2 & Medium positive correlation impact \\
3 & Strong positive correlation impact \\
\hline
\end{tabular}

\subsection{Phase III: Industry 4.0 implementation sequence}

In Table 3, 650 correlation possibilities were examined, and a specification was made between prerequisite ("V") and supporting ("U") correlation. The correlations can also have a single, double or triple influence on each other. 


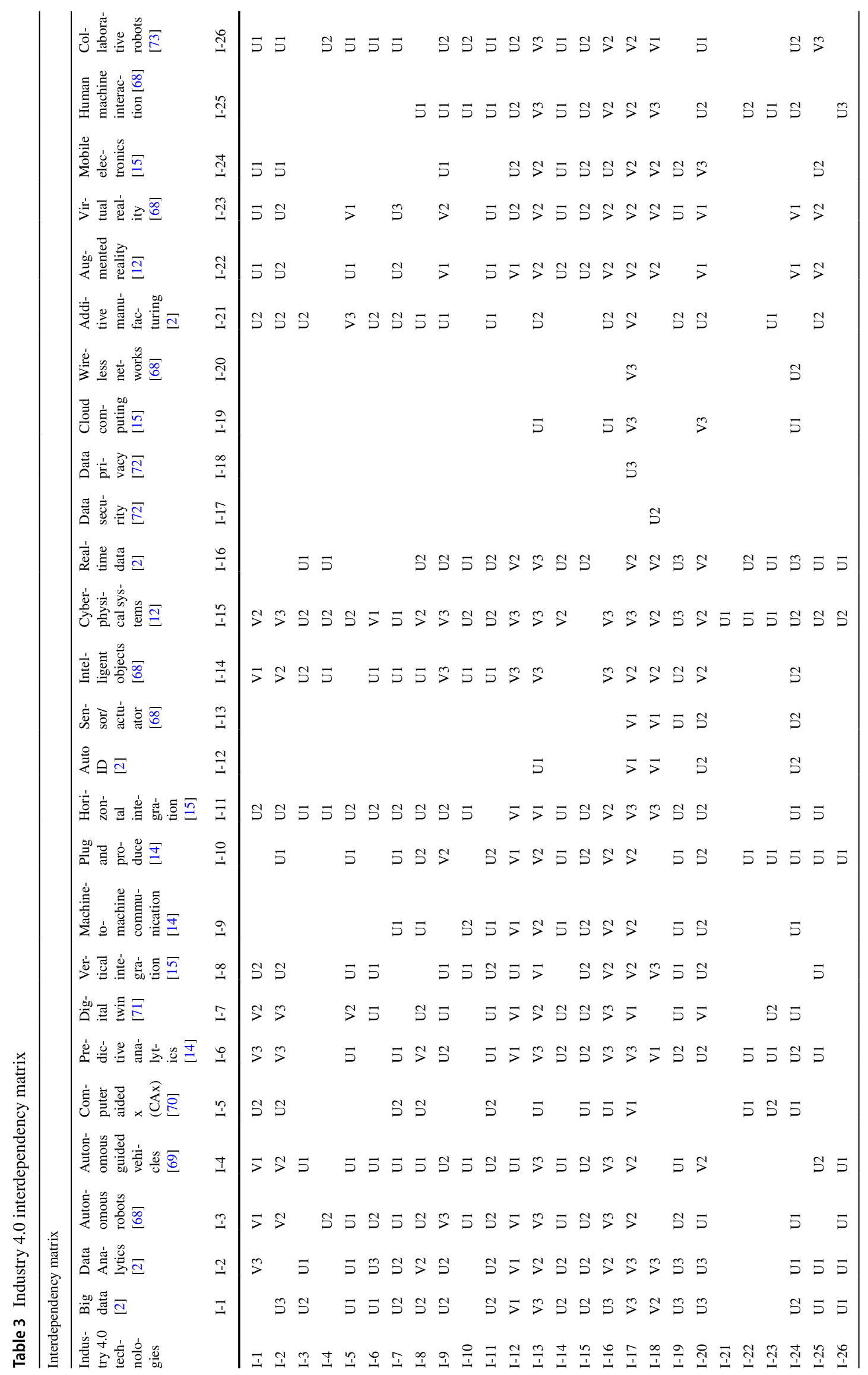


According to the experts, the use case and literature analysis, 151 technologies have a low positive correlation (1), whereas 172 elements have a medium positive correlation (2) and 53 have a strong positive correlation impact (3). Moreover, the panelists identified no negative correlation between the technologies and 125 prerequisite and 251 supportive correlations. As a result, many interactions between the individual technologies must be considered when creating an Industry 4.0 reference implementation sequence for manufacturing companies.

Based on the design structure matrix (see Table 3), an Industry 4.0 reference implementation sequence of the 26 selected technologies can be derived. Therefore, the prerequisite interrelations between the technologies should be considered. Consequently, technologies can only be initiated if all the prerequisites have been fulfilled. In addition, supportive elements are positioned as close together as possible. This procedure results in seven successive implementation levels until a cyber-physical (production) system (CPPS) can be implemented in Level 7. The levels were labeled based on the six levels of Schuh et al. [53] and extended by one additional level security (Level 1). The other levels are computerization (Level 2), connectivity (Level 3), visibility (Level 4), transparency (Level 5), predictive capacity (Level 6), and adaptability (Level 7).

The level security was additionally introduced because it is the basis for a secure and legally compliant implementation of Industrie 4.0 and is essential to prevent cyber attacks. The second and third levels rely on introducing sensor and actuator solutions, RFID tags (auto ID), a company-wide cloud, or the implementation of wireless networks to establish computerization and connectivity. Level 3 is the first one in which industrial digitization becomes visible through applications from the fields of additive manufacturing. Level 4 creates visibility by implementing human-machine interaction, machine-to-machine communication, or vertical and horizontal system integration. This level enables the horizontal networking of business processes across divisions and companies and enables data-based decision-making. In Level 5, Industry 4.0 becomes transparent due to data analytics, which allows analyzing complex cause-effect relationships in manufacturing companies. Moreover, employees can be supported in the decision-making processes by using augmented or virtual reality. The predictive capability in level 6 is then based on the independent machine communicating over several control levels and forming the first autonomous control circuits. Finally, Industry 4.0 is completed with adaptability in a cyber-physical production system (CPPS) in Level 7. Such a CPPS can then connect objects in the real world with virtual objects and act autonomously. The Industry 4.0 reference implementation sequence for manufacturing companies is presented in Fig. 7.
The implementation sequence (Fig. 7) only shows the earliest possible start time, based on the prerequisites to be met entirely for upstream implementation steps. In addition, the implementation sequence serves as a reference architecture and must be adapted to the requirements and circumstances of the individual company.

\section{Discussion and perspective}

The Industry 4.0 reference implementation sequence can not directly be compared with existing literature, as the publications of the Industry 4.0 implementation models do not consider the main technology fields down to the level of the selected technologies. However, the identified models confirm the identified interactions between technologies $[23,26,74-76]$. Therefore, the validation is based on five interviews with experts from industry and science to discuss the results and open new research perspectives. The Industry 4.0 reference implementation sequence and the interdependency matrix correspond to the expert's opinions. It was also pointed out that the interdependency matrix and implementation sequence significantly and transparently support companies' implementation of Industry 4.0 in production. However, the reference architecture should also include organizational and personal principles and methods for a holistic transformation. Also, the technology's introduction duration and the needed resources should be analyzed and investigated to estimate the implementation effort.

In summary, three essential pillars for the further development and continuation of research activities could be identified based on the interdependency matrix and implementation sequence:

- Pillar 1-Extension and specification of the Industry 4.0 technologies: With the constant release of innovative technologies, the Industry 4.0 technology selection must be continuously adapted to integrate emerging technologies into the interdependency matrix. Additionally, Key Performance Indicators (KPI) should specify the Industry 4.0 technologies. By setting up a KPI model, the benefits and implementation efforts for companies can be indicated. Besides, each technology's implementation duration needs to be determined to analyze the effort required for an Industry 4.0 implementation roadmap.

- Pillar 2-Company-specific simulation model The introduction of Industry 4.0 in manufacturing companies must consider company-specific conditions and requirements. Therefore, various implementation scenarios, including personnel, time, and monetary resources, should be identified and evaluated. Based on the interdependency matrix (Table 3) and the results of Pillar 1, a user-friendly software application needs to be developed to support 
Fig. 7 Industry 4.0 implementation sequence
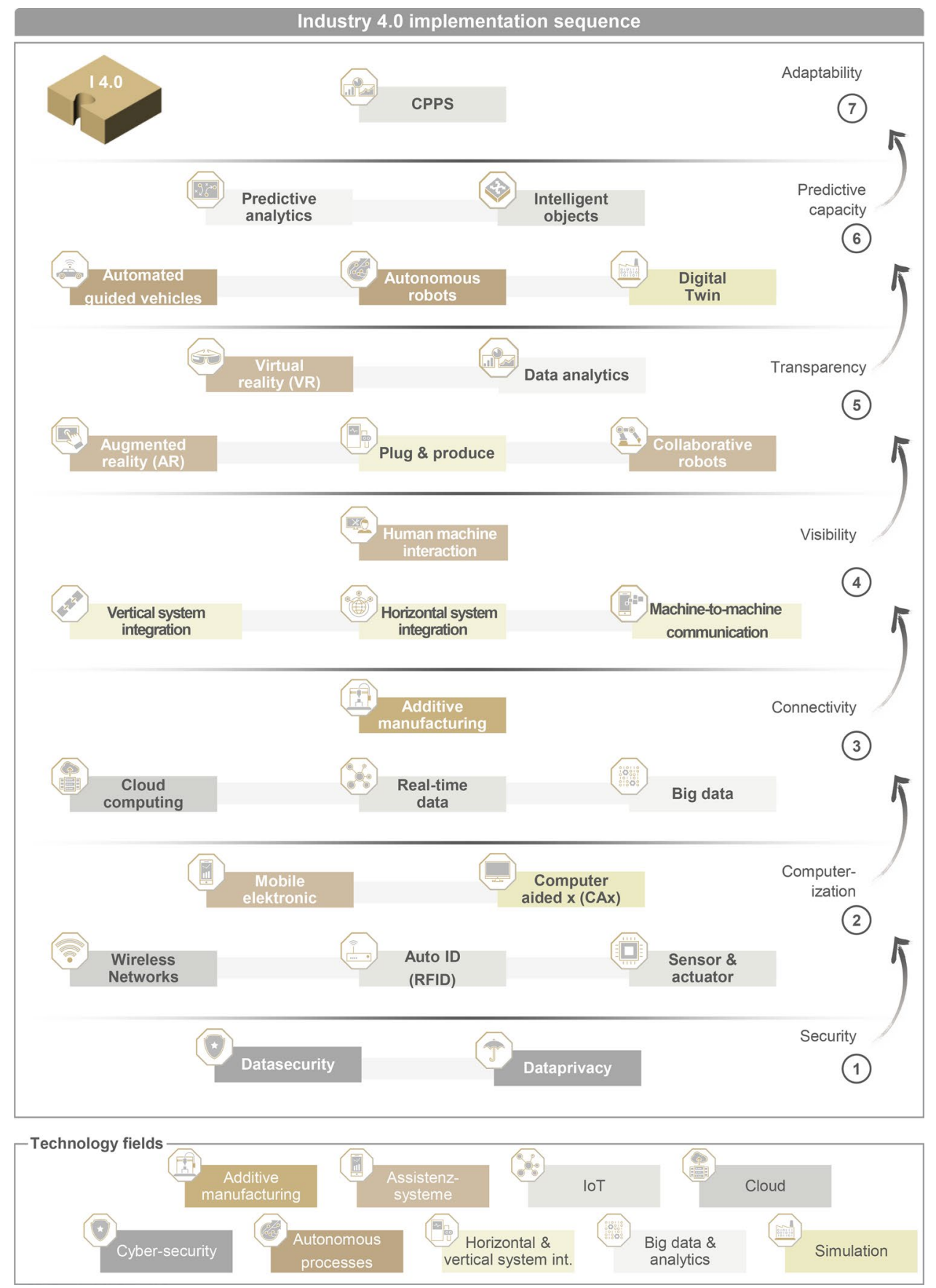

companies in deriving a company-specific Industry 4.0 implementation roadmap.

- Pillar 3-Holistic transformation process Concerning the human-technology-organization model [8], a successful digital transformation requires a holistic development of the production processes [77]. While Industry 4.0 is technology-oriented, Lean Production focuses on the organization and its people [78, 79]. Therefore a combined implementation strategy for Lean Production and Industry 4.0 should be developed. The interaction of these two production paradigms promises further potential for efficiency and cost savings in production [6].

\section{Conclusion}

Industry 4.0 has the potential to deal with fundamental and complex challenges, like globalization or mass personalization. However, the systematic implementation of Industry 4.0 technologies in production is complex due to a lack of 
expertise and research in the interactions between the single technologies.

This paper presents an Industry 4.0 interdependency matrix and an Industry 4.0 reference implementation sequence for manufacturing companies based on a scientifically substantiated approach. First, the interdependency matrix presents the one-to-one correlation of highly relevant Industry 4.0 technologies and indicates each correlation's impact and type. Therefore, relevant Industry 4.0 technologies have been identified and selected, and the interdependencies have been investigated using a comprehensive literature review and use case analysis. In addition, an indepth Delphi study method with experts from industry and research was carried out to identify the one-to-one impact and type between the technologies. The results were presented in an interdependency matrix and transferred into an Industry 4.0 reference implementation sequence for manufacturing companies.

Five semi-structured interviews with experts from science and industry have been conducted to validate the implementation sequence and open new research perspectives. In addition to the possibility of adapting the sequence to company-specific requirements and integrating supplementary information, a research perspective and enhancement of the implementation strategy is the integration of Lean Production. Thus, companies can be supported in the holistic transformation process in the sense of the human-technology-organization model.

Funding Open Access funding enabled and organized by Projekt DEAL.

Open Access This article is licensed under a Creative Commons Attribution 4.0 International License, which permits use, sharing, adaptation, distribution and reproduction in any medium or format, as long as you give appropriate credit to the original author(s) and the source, provide a link to the Creative Commons licence, and indicate if changes were made. The images or other third party material in this article are included in the article's Creative Commons licence, unless indicated otherwise in a credit line to the material. If material is not included in the article's Creative Commons licence and your intended use is not permitted by statutory regulation or exceeds the permitted use, you will need to obtain permission directly from the copyright holder. To view a copy of this licence, visit http://creativecommons.org/licenses/by/4.0/.

\section{References}

1. Herder CF, Aurich JC (2015) Concept for assessment of manualassembly technologies. AMM 794:43-50. https://doi.org/10.4028/ www.scientific.net/AMM.794.43

2. Reinhart G (ed) (2017) Handbuch Industrie 4.0: Geschäftsmodelle, Prozesse, Technik. Hanser, München

3. Wagner RM (2018) Industrie 4.0 für die Praxis: Mit realen Fallbeispielen aus mittelständischen Unternehmen und vielen umsetzbaren Tipps. Springer Gabler, Wiesbaden
4. Obermaier R (2016) Industrie 4.0 als unternehmerische Gestaltungsaufgabe: Betriebswirtschaftliche, technische und rechtliche Herausforderungen. Springer Gabler, Wiesbaden

5. Kellner F, Lienland B, Lukesch M (2020) Produktionswirtschaft: Planung, Steuerung und Industrie 4.0, 2., aktualisierte und erweiterte Auflage. Lehrbuch. Springer Gabler, Berlin

6. Dillinger F, Formann F, Reinhart G (2020) Lean Production und Industrie 4.0 in der Produktion: Eine Studie zur Wechselwirkung und den gemeinsamen Potenzialen. ZWF 115:738-741. https:// doi.org/10.3139/104.112415

7. Ramsauer C (2013) Industrie 4.0 - die Produktion der Zukunft. WINGbusiness, 3:6-12

8. Veile JW, Kiel D, Müller JM et al (2020) Lessons learned from Industry 4.0 implementation in the German manufacturing industry. JMTM 31:977-997. https://doi.org/10.1108/ JMTM-08-2018-0270

9. Bousdekis A, Lepenioti K, Apostolou D et al (2019) Decision making in predictive maintenance: literature review and research agenda for industry 4.0. IFAC-PapersOnLine 52:607612. https://doi.org/10.1016/j.ifacol.2019.11.226

10. Kumar RS, Pugazhendhi S (2012) Information sharing in supply chains: an overview. Proc Eng 38:2147-2154. https://doi.org/ 10.1016/j.proeng.2012.06.258

11. Berg A (2020) Digitalisierung der Wirtschaft. https://bitkom. org/sites/default/files/2020-03/bitkom-charts-digitalisierungder-wirtschaft-01-04-2020_final.pdf. Accessed 28 Nov 2021

12. Bauernhans1 T, ten Hompel M, Vogel-Heuser B (2014) Industrie 4.0 in Produktion, Automatisierung und Logistik: Anwendung, Technologien, Migration. Springer Fachmedien Wiesbaden, Wiesbaden

13. Cohen Y, Faccio M, Pilati F et al (2019) Design and management of digital manufacturing and assembly systems in the Industry 4.0 era. Int J Adv Manuf Technol 105:3565-3577. https://doi.org/10.1007/s00170-019-04595-0

14. Oztemel E, Gursev S (2020) Literature review of Industry 4.0 and related technologies. J Intell Manuf 31:127-182. https:// doi.org/10.1007/S10845-018-1433-8

15. Rüßmann M, Lorenz M, Gerbert P, Waldner M, Justus J, Engel P, Harnisch M. Industry 4.0: The Future of Productivity andGrowth in Manufacturing Industries. https://www.bcg.com/ dede/publications/2015/engineered_products_project_busin ess_industry_4_future_productivity_growth_manufacturing industries. Accessed 28 Nov 2021

16. Gilchrist A (2016) Industry 4.0: the industrial internet of things. Apress, New York

17. Dai H-N, Wang H, Xu G et al (2020) Big data analytics for manufacturing internet of things: opportunities, challenges and enabling technologies. Enterp Inf Syst 14:1279-1303. https:// doi.org/10.1080/17517575.2019.1633689

18. Yang X, Plewe DA (2016) Assistance systems in manufacturing: a systematic review. In: Schlick C, Trzcieliński S (eds) Advances in ergonomics of manufacturing: managing the enterprise of the future, vol 490. Springer International Publishing, Cham, pp 279-289

19. Dillinger F, Messmer C, Reinhart G (2021) Industrie-4.0-Technologiekreis für produzierende Unternehmen. ZWF 116:639643. https://doi.org/10.1515/zwf-2021-0145

20. Tropschuh B, Korder S, Dillinger F et al (2020) Activity-based shop floor management-a concept to enhance flexibility. https://doi.org/10.15488/9667

21. Bosse CK, Zink KJ (2019) Arbeit 4.0 im Mittelstand: Chancen und Herausforderungen des digitalen Wandels für KMU. Springer Gabler, Berlin

22. Tropschuh B, Dillinger F, Gärtner Q et al. (2021) Structure of a Socio-Technical Learning and Innovation Factory 269:3-11. https://doi.org/10.1007/978-3-030-80000-0_1 
23. Pistorius $\mathbf{J}$ (2020) Industrie 40 - Schlüsseltechnologien für die Produktion: Grundlagen $\bullet$ Potenziale $\bullet$ Anwendungen. Springer Vieweg, Berlin

24. Mell PM, Grance T (2011) The NIST definition of cloud computing. National Institute of Standards and Technology, Gaithersburg

25. Fastermann P (2016) 3D-Drucken: Wie die generative Fertigungstechnik funktioniert, 2., aktualisierte. Technik im Fokus. Springer Vieweg, Berlin

26. Huber W (2016) Industrie 4.0 in der Automobilproduktion: Ein Praxisbuch. Springer Fachmedien Wiesbaden, Wiesbaden

27. Grebe M, Rüßmann M, Leyh M et al. (2021) The Leaders' Path to Digital Value. Germany-DE

28. Becker J, Knackstedt R, Pöppelbuß J (2009) Entwicklung von Reifegradmodellen für das IT-Management. Wirtsch Inf 51:249260. https://doi.org/10.1007/s11576-009-0167-9

29. Ustundag A (2018) Industry 4.0. Springer Series in Advanced Manufacturing Ser. Springer International Publishing AG, Cham

30. Anderl R, Picard A, Fleischer J et al. (2015) Guideline Industrie 4.0-Guiding principles for the implementation of Industrie 4.0 in small and medium sized businesses, Frankfurt

31. Berghaus S, Back A (2016) Gestaltungsbereiche der Digitalen Transformation von Unternehmen: Entwicklung eines Reifegradmodells. Die Unternehmung 70:98-123. https://doi.org/10.5771/ 0042-059X-2016-2-98

32. Canetta L, Barni A, Montini E (2018) Development of a digitalization maturity model for the manufacturing sector. IEE. https:// doi.org/10.1109/ICE.2018.8436292

33. Carolis A de, Macchi M, Negri E et al (2018) Guiding manufacturing companies towards digitalization a methodology for supporting manufacturing companies in defining their digitalization roadmap: A methodology for supporting manufacturing companies in defining their digitalization roadmap. In: International Conference on Engineering, Technology and Innovation (ICE/ ITMC):487-495. https://doi.org/10.1109/ICE.2017.8279925

34. Colli M, Berger U, Bockholt M et al (2019) A maturity assessment approach for conceiving context-specific roadmaps in the Industry 4.0 era. Annu Rev Control 48:165-177. https://doi.org/10.1016/j. arcontrol.2019.06.001

35. Ganzarain J, Errasti N (2016) Three stage maturity model in SME's toward industry 4.0. J Ind Eng Manag 9(5):1119. https:// doi.org/10.3926/JIEM.2073

36. Geissbauer R, Vedso J, Schrauf S (2016) Building the digital enterprise - PWC 2016 Global Industry Survey. https://www. pwc. com/gx/en/industries/industries-4.0/landing-page/industry4.0-building-your-digital-enterprise-april-2016.pdf. Accessed 28 Nov 2021

37. Gökalp E, Şener U, Eren PE (2017) Development of an assessment model for industry 4.0: industry 40-MM, vol 770. Springer, Cham, pp 128-142

38. Hamidi SR, Aziz AA, Shuhidan SM et al (2018) SMEs maturity model assessment of IR4.0 digital transformation, vol 739. Springer, Singapore, pp 721-732

39. Schallmo DRA, Lang K, Hasler D et al (2021) An approach for a digital maturity model for smes based on their requirements. In: Schallmo DRA, Tidd J (eds) Digitalization. Springer International Publishing, Cham, pp 87-101

40. Horvat D, Stahlecker T, Zenker A et al (2018) A conceptual approach to analysing manufacturing companies' profiles concerning Industry 4.0 in emerging economies. Proc Manuf 17:419-426. https://doi.org/10.1016/j.promfg.2018.10.065

41. Liebrecht C, Kandler M, Lang M et al (2021) Decision support for the implementation of Industry 4.0 methods: Toolbox, Assessment and Implementation Sequences for Industry 4.0. J Manuf Syst 58:412-430. https://doi.org/10.1016/j.jmsy.2020.12.008
42. Jung K, Kulvatunyou B, Choi S et al (2017) An overview of a smart manufacturing system readiness assessment. IFIP Adv Inf Commun Technol 488:705-712. https://doi.org/10.1007/978-3319-51133-7_83

43. Demircan Keskin F, Kabasakal İ, Kaymaz Y et al. (2019) An Assessment Model for Organizational Adoption of Industry 4.0 Based on Multi-criteria Decision Techniques. In: Durakbasa NM, Gencyilmaz MG (eds) Proceedings of the International Symposium for Production Research 2018. Springer International Publishing, Cham, pp 85-100

44. Klötzer C, Pflaum A (2017) Toward the Development of a Maturity Model for Digitalization within the Manufacturing Industry's Supply Chain. In: Proceedings of the 50th Hawaii International Conference on System Sciences. Hawaii International Conference on System Sciences, pp 4210-4219

45. Lanza G, Nyhuis P, Ansari SM et al (2016) Befähigungs- und Einführungsstrategien für Industrie 4.0: Vorstellung eines reifegradbasierten Ansatzes zur Implementierung von Industrie 4.0. ZWF 111:76-79. https://doi.org/10.3139/104.111462

46. Lee J, Jun S, Chang T-W et al (2017) A smartness assessment framework for smart factories using analytic network process. Sustainability 9:794. https://doi.org/10.3390/su9050794

47. Leyh C, Schäffer T, Bley K et al. (2016) SIMMI 4.0-A maturity model for classifying the enterprise-wide IT and software landscape focusing on industry 4.0. In: Federated Conference on Computer Science and Information Systems 2016 8:1297-1302. https://doi.org/10.15439/2016F478

48. Lichtblau K, Stich V, Bertenrath R et al. (2015) Industrie 4.0-readiness, Aachen

49. Methavitakul B, Santiteerakul S (2018) Analysis of key dimension and sub-dimension for Supply Chian of Industry to fourth Industry Performance Measurement, pp 191-195. https://doi. org/10.1109/SOLI.2018.8476765

50. Basl J, Doucek P (2019) A metamodel for evaluating enterprise readiness in the context of industry 4.0. Information (Switzerland) 10:89. https://doi.org/10.3390/info10030089

51. Rauch E, Unterhofer M, Rojas RA et al (2020) A maturity levelbased assessment tool to enhance the implementation of industry 4.0 in small and medium-sized enterprises. Sustainability 12:3559. https://doi.org/10.3390/su12093559

52. Reuter C, Gartzen T, Prote J-P et al (2016) Industrie-4.0-Audit für produzierende Unternehmen. https://www.ingenieur.de/ fachmedien/vdi-z/industrie-4-0/industrie-4-0-audit-fuer-produ zierende-unternehmen/. Accessed 28 Nov 2021

53. Schuh G, Anderl R, Dumitrescu R et al (2020) Der Industrie 4.0 Maturity Index in der betrieblichen Anwendung - aktuelle Herausforderungen, Fallbeispiele und Entwicklungstrends (acatech KOOPERATION): Aktuelle Herausforderungen, Fallbeispiele und Entwicklungstrends

54. Schumacher A, Erol S, Sihn W (2016) A maturity model for assessing industry 4.0 readiness and maturity of manufacturing enterprises. Proc CIRP 52:161-166. https://doi.org/10.1016/j. procir.2016.07.040

55. Scremin L, Armellini F, Brun A et al (2018) Towards a framework for assessing the maturity of manufacturing companies in industry 4.0 adoption. In: Martinez F, Brunet-Thornton R (eds) Analyzing the impacts of industry 4.0 in modern business environments. IGI Global Disseminator of Knowledge, Hershey, pp 224-254

56. Sjödin DR, Parida V, Leksell M et al (2018) Smart factory implementation and process innovation. Res Technol Manag 61:22-31. https://doi.org/10.1080/08956308.2018.1471277

57. Becker P (2021) Industrie 4.0 Reifegrad-Test. https://www. connected-production.de/industrie-4-0-reifegrad-test/. Accessed 28 Nov 2021 
58. Aull F (2013) Modell zur Ableitung effizienter Implementierungsstrategien für Lean-Production-Methoden. Zugl.: München, Techn. Univ., Diss., 2012. Forschungsberichte IWB, vol 275. Utz, München

59. Dillinger F, Kagerer M, Reinhart G (2021) Concept for the development of a Lean 4.0 reference implementation strategy for manufacturing companies. Proc CIRP 104:330-335. https:// doi.org/10.1016/j.procir.2021.11.056

60. Rowley J, Slack F (2004) Conducting a literature review. Manag Res News 27:31-39. https://doi.org/10.1108/014091704107841 85

61. Federal Ministry for Economic Affairs and Energy (2021) Plattform Industrie 4.0. https://www.plattform-i40.de/PI40/Navigation/ Karte/SiteGlobals/Forms/Formulare/EN/map-use-cases-formular. html. Accessed 28 Nov 2021

62. Lindemann U, Maurer M, Braun T (2009) Structural complexity management: an approach for the field of product design. Springer Berlin Heidelberg, Berlin

63. Dalkey N, Helmer O (1963) An experimental application of the DELPHI method to the use of experts. Manag Sci 9:458-467. https://doi.org/10.1287/mnsc.9.3.458

64. Linstone HA, Turoff M (1975) The Delphi method: techniques and applications. Addison-Wesley, Reading

65. Grime MM, Wright G (2014) Delphi method. In: Balakrishnan N, Colton T, Everitt B et al (eds) Wiley StatsRef: statistics reference online. Wiley, Chichester, pp 1-6

66. Vernim S, Krauel M, Reinhart G (2021) Identification of digitization trends and use cases in assembly. Proc CIRP 97:136-141. https://doi.org/10.1016/j.procir.2020.05.215

67. Wichmann RL, Eisenbart B, Gericke K (2019) The direction of industry: a literature review on industry 4.0. Proc Int Conf Eng Des 1:2129-2138. https://doi.org/10.1017/dsi.2019.219

68. Alcácer V, Cruz-Machado V (2019) Scanning the Industry 4.0: a literature review on technologies for manufacturing systems. Eng Sci Technol Int J 22:899-919. https://doi.org/10.1016/j.jestch. 2019.01.006

69. Bauernhansl T (2016) Weckruf für Unternehmen: Warum wir ein einheitliches Verständnis für Industrie 4.0 brauchen. ZWF 111:453-457. https://doi.org/10.3139/104.111553
70. Vaidya S, Ambad P, Bhosle S (2018) Industry 4.0-a glimpse. Proc Manuf 20:233-238. https://doi.org/10.1016/j.promfg.2018. 02.034

71. Qi Q, Tao F (2018) Digital twin and big data towards smart manufacturing and industry 4.0: 360 degree comparison. IEEE Access 6:3585-3593. https://doi.org/10.1109/ACCESS.2018.2793265

72. Lenhard TH (2017) Datensicherheit: Technische und organisatorische Schutzmaßnahmen gegen Datenverlust und Computerkriminalität. Springer Fachmedien Wiesbaden, Wiesbaden

73. Schuh G, Prote J-P, Molitor M et al (2019) Produktivitätsbaukasten 4.0. ZWF 114:408-411. https://doi.org/10.3139/104.112110

74. Bartodziej CJ (2017) The concept industry 4.0. Springer Fachmedien Wiesbaden, Wiesbaden

75. Geisberger E, Broy M (2012) AgendaCPS: Integrierte Forschungsagenda; Cyber-physical systems. acatech Studie. Springer, Berlin

76. Bracht U, Geckler D, Wenzel S (2018) Digitale Fabrik: Methoden und Praxisbeispiele, 2, aktualisierte und erweiterte. VDI-Buch. Springer Vieweg, Berlin

77. Dillinger F, Kagerer M, Brandl F et al (2021) Managing the systemic transition from a learning factory for lean production (LSP) to an innovation lab for smart \& lean processes at iwb (TUM). SSRN J. https://doi.org/10.2139/ssrn.3862079

78. Metternich J, Müller M, Meudt T et al (2017) Lean 4.0 - zwischen Widerspruch und Vision. ZWF 112:346-348. https://doi.org/10. 3139/104.111717

79. Tropschuh B, Dillinger F, Korder S et al (2021) Industrie 5.0 - ein menschzentrierter Ansatz. ZWF 116:387-392. https://doi.org/10. 1515/zwf-2021-0091

Publisher's Note Springer Nature remains neutral with regard to jurisdictional claims in published maps and institutional affiliations. 